\title{
Numerical Simulations and Analysis of June 16, 2010 Heavy Rainfall Event over Singapore Using the WRFV3 Model
}

\author{
B. H. Vaid ${ }^{1,2}$ \\ ${ }^{1}$ TMSI, National University of Singapore, Singapore \\ ${ }^{2}$ Department of Applied Sciences, Raj Kumar Goel Institute of Technology for Women, Near Jain Tube, \\ Delhi Meerut Road, Ghaziabad 200203, India \\ Correspondence should be addressed to B. H. Vaid; bakshi32@gmail.com
}

Received 3 September 2012; Revised 6 December 2012; Accepted 6 January 2013

Academic Editor: Dimitris G. Kaskaoutis

Copyright (c) 2013 B. H. Vaid. This is an open access article distributed under the Creative Commons Attribution License, which permits unrestricted use, distribution, and reproduction in any medium, provided the original work is properly cited.

\begin{abstract}
The Numerical Simulations of the June 16, 2010, Heavy Rainfall Event over Singapore are highlighted by an unprecedented precipitation which produced widespread, massive flooding in and around Singapore. The objective of this study is to check the ability of Weather Research Forecasting version 3 (WRFV3) model to predict the heavy rain event over Singapore. Results suggest that simulated precipitation amounts are sensitive to the choice of cumulus parameterization. Various model configurations with initial and boundary conditions from the NCEP Final Global Analysis (FNL), convective and microphysical process parameterizations, and nested-grid interactions have been tested with 48-hour (June 15-17, 2010) integrations of the WRFV3. The spatial distributions of large-scale circulation and dynamical and thermodynamical fields have been simulated reasonably well in the model. The model produced maximum precipitation of $\sim 5 \mathrm{~cm}$ over Changi airport which is very near to observation $(6.4 \mathrm{~cm}$ recorded at Changi airport). The model simulated dynamic and thermodynamic features at 00UTC of June 16, 2010, lead to understand the structure of the mesoscale convective system (MCS) that caused the extreme precipitation over Singapore. It is observed that Singapore heavy rain was the result of an interaction of synoptic-scale weather systems with the mesoscale features.
\end{abstract}

\section{Introduction}

On 16th June 2010, a heavy rainfall event occurred in Singapore producing devastating flash flood and tremendous amount of property damage (Singapore's national water agency (PUB) report, Annual Weather Review, 2010, NEA, Singapore). Heavy rainfall is usually resulted from individual mesoscale storms or mesoscale convective systems (MCSs) embedded in synoptic-scale disturbances [1]. High-resolution observations and numerical modeling technique are needed to better predict heavy rainfall events and understand the evolution and development mechanisms of mesoscale convection and storms responsible for heavy rainfall. In this study, a highresolution version of the WRFV3 (Weather Research and Forecasting Version 3) model is used to investigate the predictability of heavy rainfall over Singapore and try to exploit the mesoscale convective systems which are highly interacting with synoptic-scale environment. WRFV3 has been used successfully for predicting heavy rainfall which occurred in many different countries and for understanding the associated convective systems [2-7]. The objective of the present study is to identify the best possible microphysics, cumulus, and PBL scheme for simulation of heavy rainfall events over Singapore, to assess the predictability of the intensity of the event, and to understand the dynamic and thermodynamic characteristics of Mesoscale Convective System (MCS) that lead to heavy precipitation over Singapore.

\section{Data}

In the present study, $1.0 \times 1.0$ degree gridded NCEP FNL (Final) Operational Global Analysis and Global Forecast System (GFS) data has been used. FNL product is from the Global Data Assimilation System (GDAS), which continuously collects observational data from the Global Telecommunications System (GTS), and other sources, for many analyses. The FNLs are made with the same model which NCEP uses in the Global Forecast System (GFS), but the FNLs are prepared about an hour or so after the GFS is initialized. The FNLs are delayed, so that more observational 
TABLE 1: Microphysics, Cu-physics, and PBL schemes.

\begin{tabular}{lll}
\hline Microphysics options & Cumulus parameterization & Boundary-layer option \\
\hline WSM 6-class graupel & Kain-Fritsch (new Eta) scheme & \\
WDM6 & Grell-Devenyi ensemble scheme (GD) & YSU scheme \\
Lin et al. scheme & New Grell scheme (G3) & Mellor-Yamada-Janjic (Eta) TKE scheme \\
& Betts-Miller-J & \\
\hline
\end{tabular}

data can be used. Moreover, we also used the Tropical Rainfall Measuring Mission (TRMM) rainfall remote sensing data. Rainfall is very variable in space and time. Accurate rainfall measurement in the tropics has long been and remains a difficult task. Before the existence of satellite remote sensing, there was very little rainfall measurement data over the open oceans and undeveloped countries. TRMM's TMI and PR instruments have greatly improved this situation by scanning the entire globe between $35 \mathrm{~N}$ and $35 \mathrm{~S}$ and supplying excellent coverage daily in the tropics. TRMM is a joint USJapan satellite mission to monitor tropical and subtropical precipitation and to estimate its associated latent heating. TRMM is used as it gives the data of unprecedented accuracy. TRMM observations used in the study are of $.25 \times .25$ degree resolutions. So, only the pixel which covers Singapore's domain was used and compared with model output.

\section{Model Configuration and Experimental Setup}

Many attempts have been made to assess and evaluate the performance of numerical weather predictions from model configurations for the region, because on the basis of flood forecasting and even rainfall forecasting as well as safety evaluation model for Mumbai, the early warning could be avoiding disaster. During the last two decades, weather forecasting all over the world has greatly benefitted from the guidance provided by the Numerical Weather Prediction (NWP). Significant improvement in accuracy and reliability of NWP products has been driven by advances in numerical techniques, explosive growth in computer power, and the phenomenal increase in satellite-based soundings. The prediction of these systems is subject to the limitations of synoptic forecasting methods, which only indicate probable occurrence of heavy precipitation but not the quantity. Although numerical models provide the quantitative prediction of precipitation, they are subject to the limitations of initial data, model dynamics, and physics which can lead to uncertainties model output. Uncertainties are "data uncertainties," "modeling uncertainties," "completeness uncertainties." Data uncertainties arise from the quality or appropriateness of the data used as inputs to models. Modeling uncertainties arise from an incomplete understanding of the modeled phenomena, or from approximations that are used in the formal representation of the processes. Completeness uncertainties refer to all omissions due to the lack of knowledge. They are, in principle, nonquantifiable and irreducible. The prediction of the mesoscale systems requires the use of highresolution atmospheric mesoscale models and observations with a mesoscale network. Some studies of the numerical

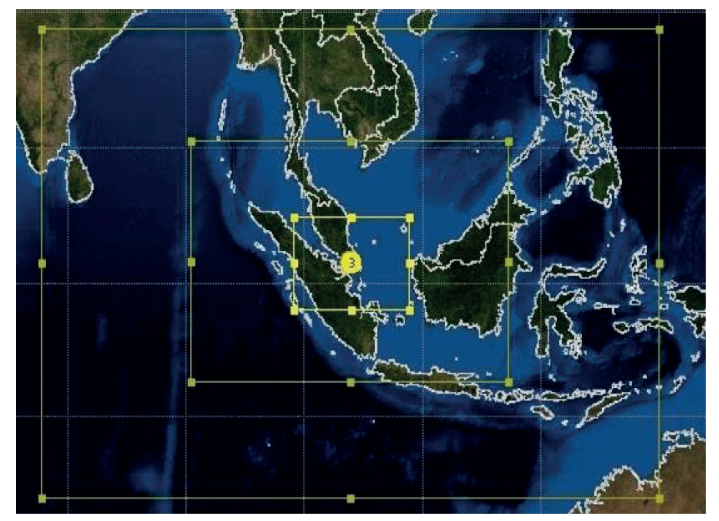

FIGURE 1: Domain used (three nested domains having resolution $27 \mathrm{~km}: 9 \mathrm{~km}: 3 \mathrm{~km})$.

prediction of heavy rainfall event over India using high resolution mesoscale models show the predictability of events with precipitation less than $20 \mathrm{~cm} /$ day $[2,3,8]$.

The model used in this study is the Advanced Research Weather Research and Forecast model (WRF) version 3.3. The WRF is the next generation forecast model and data assimilation system that has advanced both the understanding and prediction of weather. It has been designed to support operational forecasting and atmospheric research needs. The WRF model is a fully compressible, nonhydrostatic model [9]. The grid staggering is the Arakawa C grid. The model uses higher order numerics. These numerics include the Runge Kutta 2nd and 3rd order time integration schemes and 2nd to 6 th order advection schemes in both horizontal and vertical directions [10].

The model supports both idealized and real-data applications with various lateral boundary condition options. Due to meteorological complexities involved in replicating the rainfall occurrences over Singapore, the WRFV3 modeling system is tested for different physics schemes. In the present study, we tested out the possible combination of Microphysics, Cu-physics, and PBL schemes provided in the Table 1 .

It is to be noted that MYJ PBL scheme can only be used with the MYJ SFC layer scheme. Other physics options include longwave radiation from RRTM Scheme, shortwave radiation from Dudhia scheme, surface physics from unified Noah land-surface model, and Surface Clay Physics from Surface scheme Monin-Obukhov similarity theory. As grid spacings decrease, convective parameterizations become more inappropriate (and scientifically questionable given the underlying assumptions), whereas the explicit representation 
of microphysical processes can be computed for increasingly small clouds, cloud particles, water droplets, and so forth. So therefore in the present case, we conducted multinested experiments of 3 model domains of 27,9 , and $3 \mathrm{~km}$ horizontal resolution (Figure 1) to simulate a heavy rainfall case over Singapore on June 16, 2010.

In the present study, the model is forced with initial and boundary condition form NCEP Final global analysis (FNL) and model integrated $48 \mathrm{hr}$ with initial and boundary condition which started from June 15, 2010. Forcing variables are air temperature, cloud, amount/frequency, cloud liquid, water/ice, convection, geopotential height, humidity, hydrostatic pressure, ice extent, land cover, maximum/minimum temperature, planetary, boundary layer height, potential temperature, precipitable water, sea surface temperature, skin temperature, snow water, equivalent soil, moisture/water content, surface air temperature, surface pressure surface winds, tropospheric ozone, upper level winds, and wind shear.

\section{Results and Discussions}

Rainfall is an important parameter in many operational and research activities, ranging from weather forecasting to climate research. The WRFV3 model with the WSM6 microphysics is observed to provide useful information on highresolution weather phenomena over Singapore. The study demonstrated that the WSM6 schemes are competitive options in WRF by reproducing precipitating convection and associated meteorological phenomena over Singapore. Apart from this, it has been observed that performance with GD scheme is found to be the best in both spatial and temporal bases. The spatial distributions of large-scale circulation and thermodynamics features have been simulated reasonably well in this model. The model produced maximum precipitation of $\sim 5 \mathrm{~cm}$ at Changi station (the observed rainfall over Changi is $6.4 \mathrm{~cm}$ during the day). Figure 2 shows (a) TRMM rainfall (mm) and (b) WRFV3 total accumulated precipitation $(\mathrm{mm})$ for 16th June 2010. The resolution for the model precipitation shown is $3 \mathrm{~km}$. It is encouraging to note that over Singapore, the WRF-simulated accumulated rainfall on 16th June 2010 agrees well with that of observation. Note that the model simulation (shown in figure) has a much higher resolution than what the TRMM rainfall has shown. Therefore, a more detailed structure of rainfall is visible in the model simulation. Moreover, the model could also predict heavy rainfall on the central part of Singapore which seems to be in agreement with the news on floods over Singapore by Singapore national water agency (PUB).

An attempt has been carried out with available sources of data to analyse mesoscale characteristics at Singapore favorable for the formation of the event during 16th June 2010. Here, we used Finite Global Analysis (FNL) available data for the analysis. Figure 3 shows the mean sea level pressure for 00UTC of June 16, 2010 (left panel), 06UTC 16 of June, 2010 (centre panel), and 12UTC 16 June 2010 (right panel). The significant low value of mean sea level pressure is clearly evident during 00UTC of 16th June 2010 which indicates the tendency of the sudden formation of the system

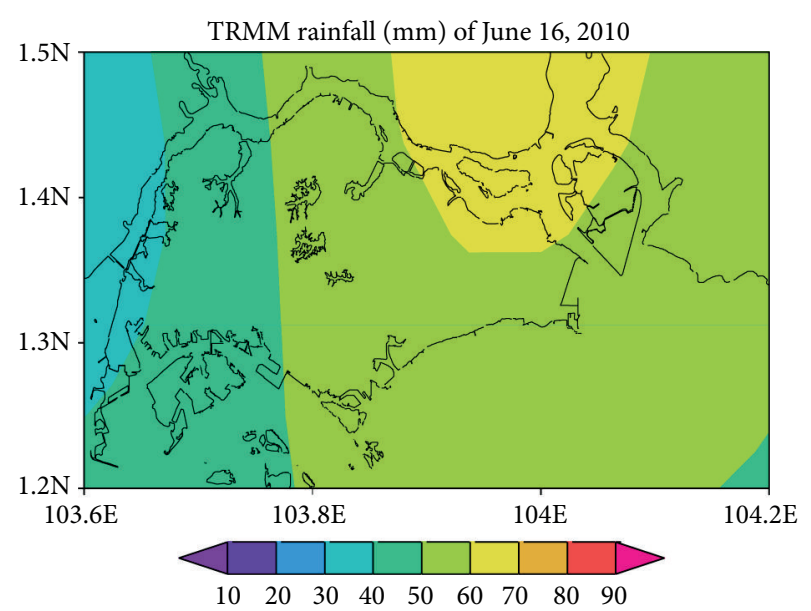

(a)

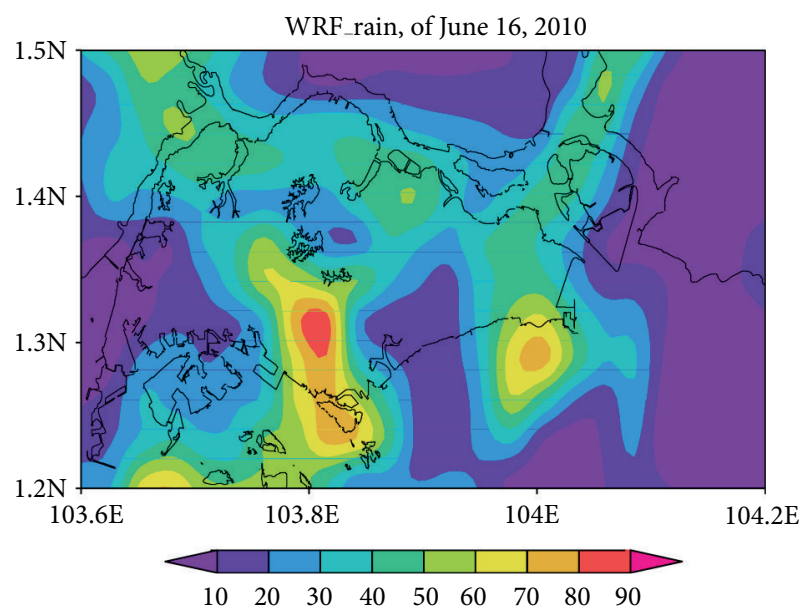

(b)

FIgURE 2: (a) TRMM rainfall (mm) and (b) WRFV3 total accumulated precipitation $(\mathrm{mm})$ for 16th June 2010. Resolution for the model precipitation shown is $3 \mathrm{~km}$.

responsible for the heavy rainfall. Figure 4 shows surface convective inhibition (CIN) for 00UTC 16 June 2010 (left panel), 06UTC of 16 June 2010 (centre panel), and 12UTC of 16 June 2010 (right panel). It clearly shows instability of the atmosphere during 00UTC of 16th June 2010. The model derived dynamical and thermodynamic fields were analyzed to understand the characteristics of the convective system which was responsible for the heavy rainfall event. Upper level atmosphere behavior is studied carefully as it is crucial in understanding its system which leads to heavy rainfall. The upper level flow and dynamics and thermodynamics can give key insights development of the system and how long it might have persisted. Since examining all heights of the atmosphere at any given time is not feasible, it is logical to choose a particular height that best represents the atmosphere at any given time. A higher than a normal height pattern at the $500 \mathrm{mb}$ level typically represents regions at the surface in which higher pressure and warmer temperatures tend to occur. Likewise, a lower than normal height pattern at $500 \mathrm{mb}$ level typically represents regions at the surface in 


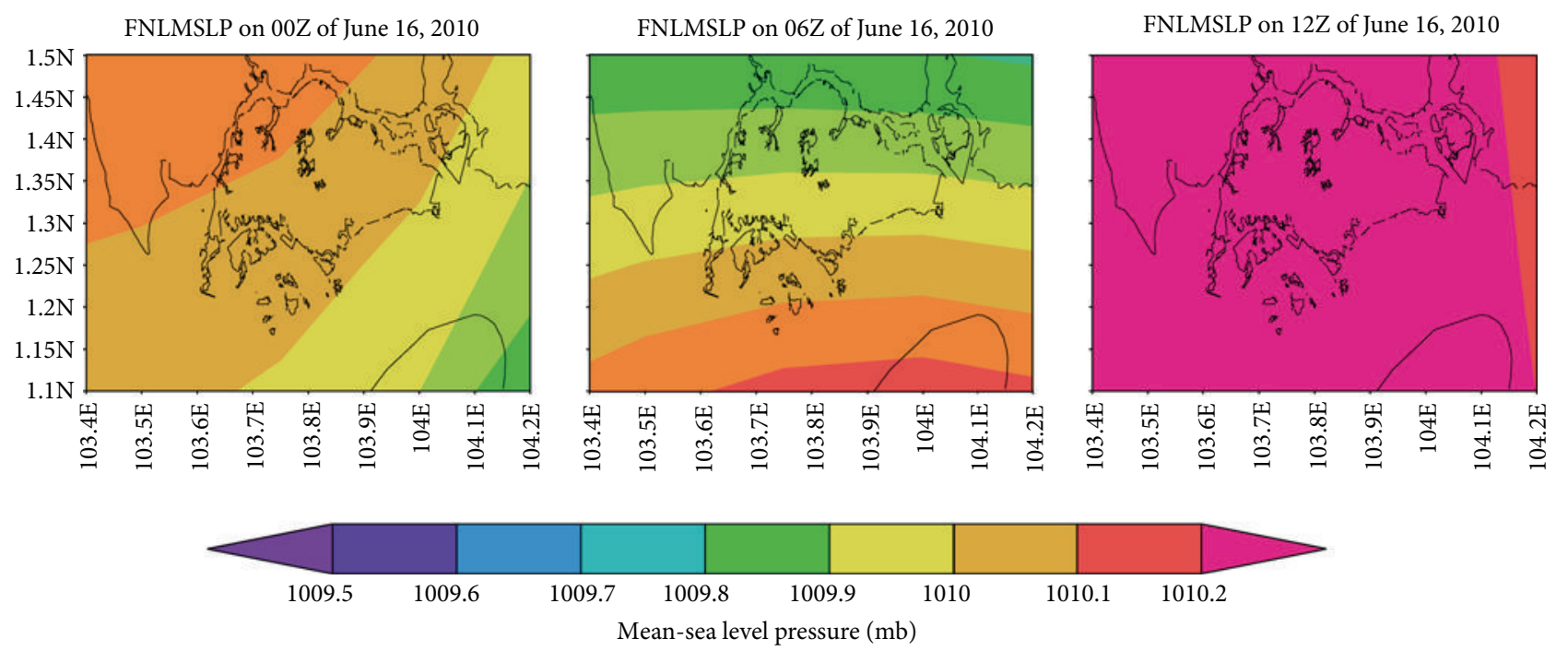

Figure 3: Mean sea level pressure for 00UTC of 16 June 2010 (left panel), 06UTC of 16 June 2010 (centre panel), and 12 UTC of 16 June 2010 (right panel).

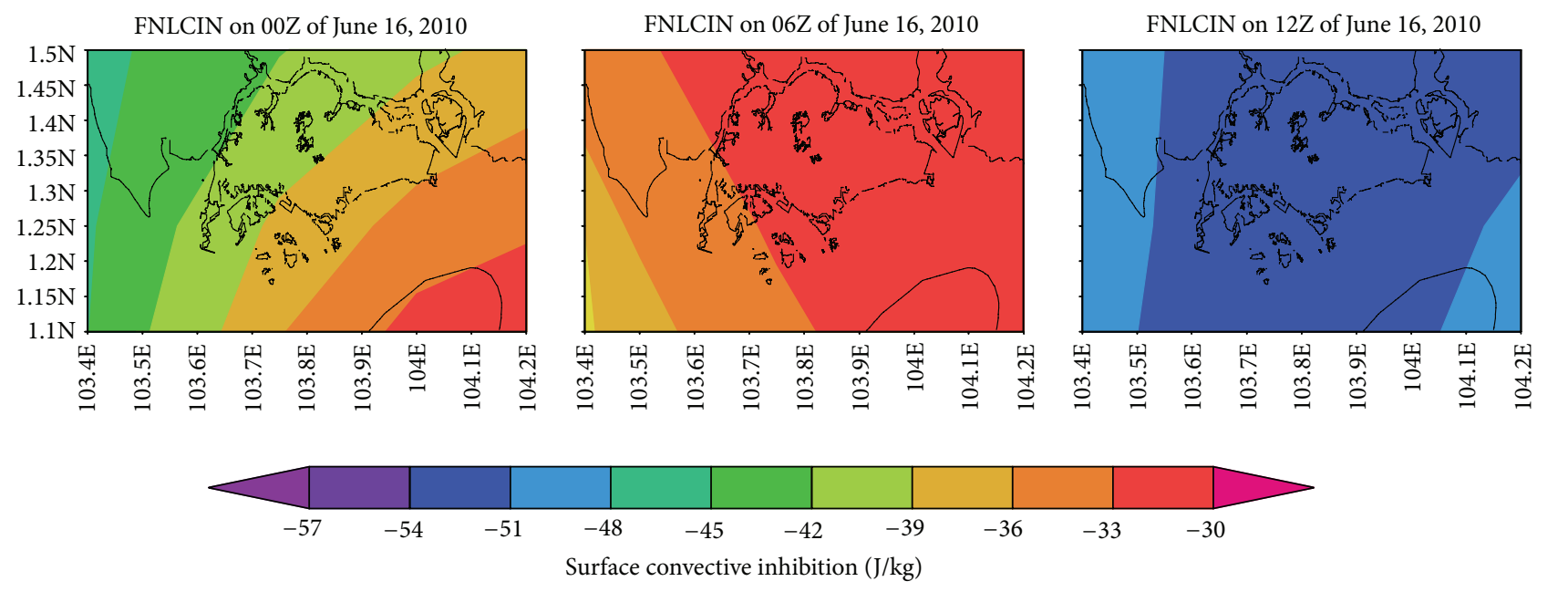

FIGURE 4: Surface convective inhibition (CIN) for 00UTC of 16 June 2010 (left panel), 06UTC of 16 June 2010 (centre panel), and 12 UTC of 16 June 2010 (right panel).

which lower pressure and cooler temperatures tend to occur. The strong values of $\mathrm{RH}$ are observed over the $500 \mathrm{mb}$ level. It is encouraging that the model could capture the dynamic and thermodynamic features which lead to form mesoscale convective system which infact produced the heavy rainfall in Singapore. Figures 5 and 6 show wind magnitude (shaded) and wind vector (arrow) at $850 \mathrm{mb}(500 \mathrm{mb})$ level on the 16th of June, 2010 (a) GFS, (b) FNL, and (c) model. WRF simulated winds are observed to be consistent and show fairly good agreement with observation. Further, a detailed study of model derived fields was carried out to explore the mesoscale characters features during the event.

The model derived dynamical and thermodynamic fields were analyzed to understand the characteristics of the convective system which was responsible for the 16th of June, 2010 heavy rainfall over Singapore. Figure 7 shows model derived relative humidity $(\mathrm{RH})$ at $500 \mathrm{mb}$ level over Singapore (left panel) and on 00UTC of the 16th of June, 2010 over Singapore with respect to vertical level (right panel). Over Singapore model predicts more than 95\% RH above the vertical level of $500 \mathrm{mb}$ (typically at 18,000 feet or $\sim 5-6$ kilometers). The time series of RH over Singapore at $500 \mathrm{mb}$ level clearly shows the time at which high $\mathrm{RH}$ was prominent. Interestingly, $\mathrm{RH}$ values were suddenly risen during 00UTC of 16 June 2010 to 06UTC June 16, 2010 which shows the model predictability of the event in agreement with the formation of system. Model derived wind direction in degrees with respect to vertical levels over Singapore on 00UTC 16 June 2010 is shown in Figure 8. The clear indication of circulation in wind is seen in between the levels 700-550 mb.

Differential model fields which can be represented by Zcomponent of wind at $250 \mathrm{mb}$ Minus Z-component of wind at $850 \mathrm{mb}$ over Singapore latitude on 00UTC of the 16th of June, 2010 have also been analyzed (Figure 9). The Z-component of 
GFS wind vectors $850 \mathrm{mb}$ on June 16, 2010

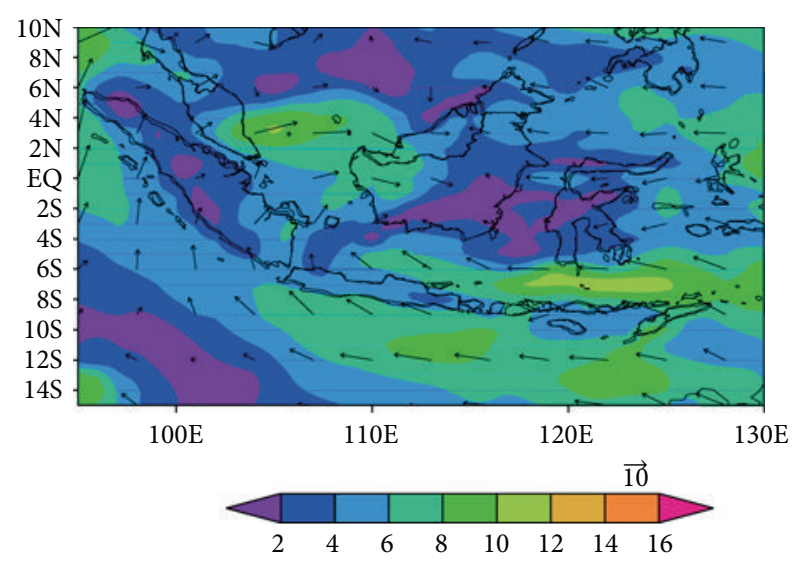

(a)
FNL wind vectors $850 \mathrm{mb}$ on June 16, 2010

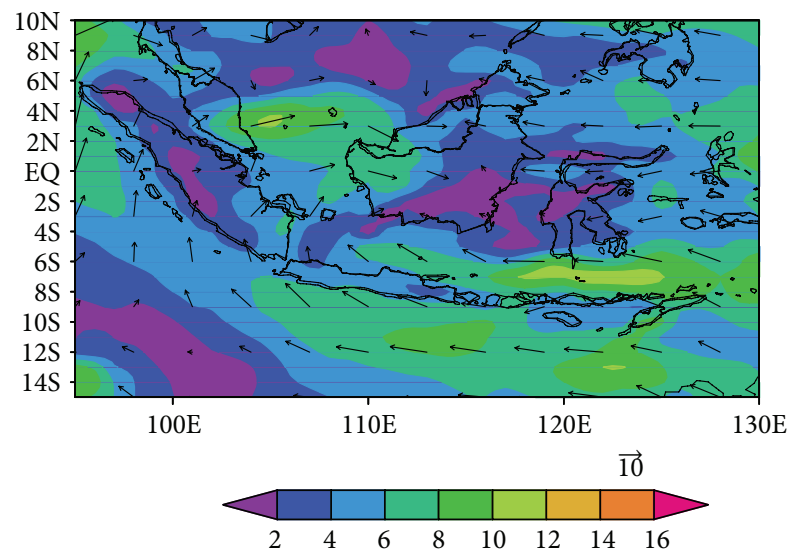

(b)

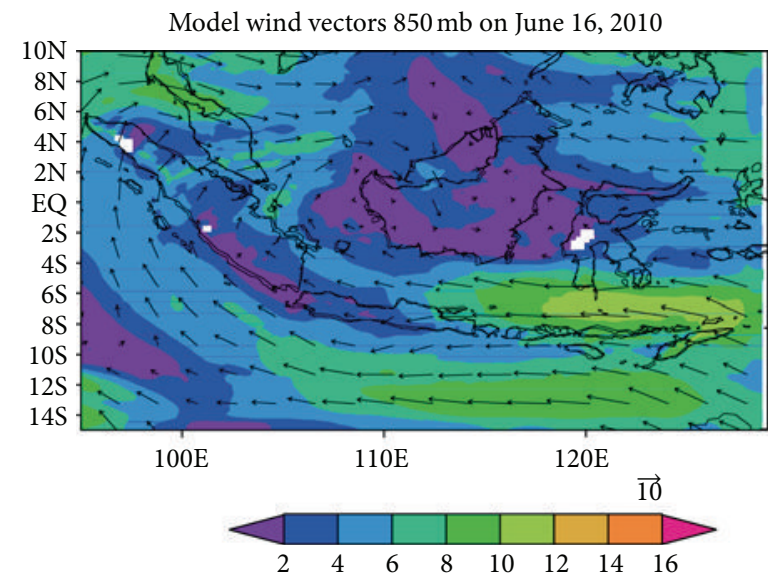

(c)

FIGURE 5: Wind magnitude (shaded) and wind vector (arrow) at $850 \mathrm{mb}$ level on 16th June 2010 (a) GFS, (b) FNL, and (c) model.

wind at $250 \mathrm{mb}$ level was higher than that $850 \mathrm{mb}$ level, which speaks of shear presented during the time for the formation of heavy rainfall and we speculate that this strong vertical Zcomponent of wind causes the cloud burst during the event, which leads to heavy rainfall. Figure 10 shows the model derived high cloud fraction in percentage over Singapore. Clearly high clouds are seen during the event. If there have been cyclone detection radar in and around Singapore, then it could have reported the clouds with heights of 5-6 km around Singapore at 00UTC of 16 June 2010.

Figure 11 shows the potential temperature (in degrees) over Singapore on 00UTC of 16 June 2010 at $400 \mathrm{mb}$ (upper panel) and at $700 \mathrm{mb}$ (lower panel). The model predicted a decrease of potential temperature from surface to $700 \mathrm{hPa}$ level and increase up to $400 \mathrm{hPa}$ during 00UTC of 16 June 2010 , indicating that potential instability increased at lower levels due to dry air capping at middle levels that caused the suppression of convection during this period and all this gave rise to sudden explosive deep convection with super cell structure producing a heavy precipitation spell. From model derived results, we can conclude that the Singapore heavy rain was the result of an interaction of synoptic-scale weather systems with the mesoscale features. Moreover, the model produced dynamical structure shows the veering of wind with height, with westerlies at lower levels and easterly at levels indicating warm air advection triggering the convection (Figure 12).

\section{Summary}

The WRFV3 was observed to make good estimate for the MCS and its timing which leads to heavy rainfall event over Singapore. The model produced maximum precipitation of $\sim 5 \mathrm{~cm}$ over Changi airport which is very near to observation (6.4 $\mathrm{cm}$ recorded at Changi airport). The model simulated circulation features shows the mesoscale characteristics of the convective system. The model simulated dynamic and thermodynamic features at 00UTC of 16th June 2010 which lead to understand the structure of the MCS that caused the heavy precipitation over Singapore. In meteorology, the vertical wind shear perspective is superior to other meteorological parameters, because it establishes the kind of physical cause and effect link between storm structure and 


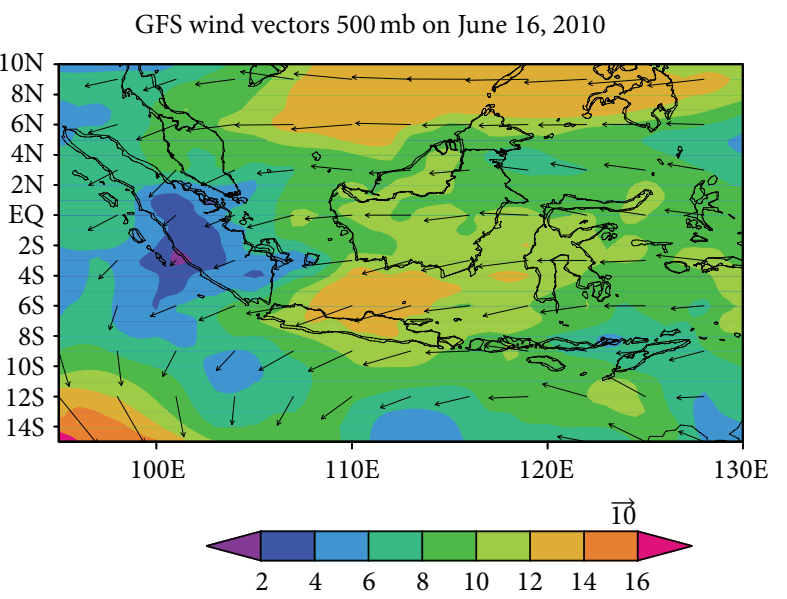

(a)

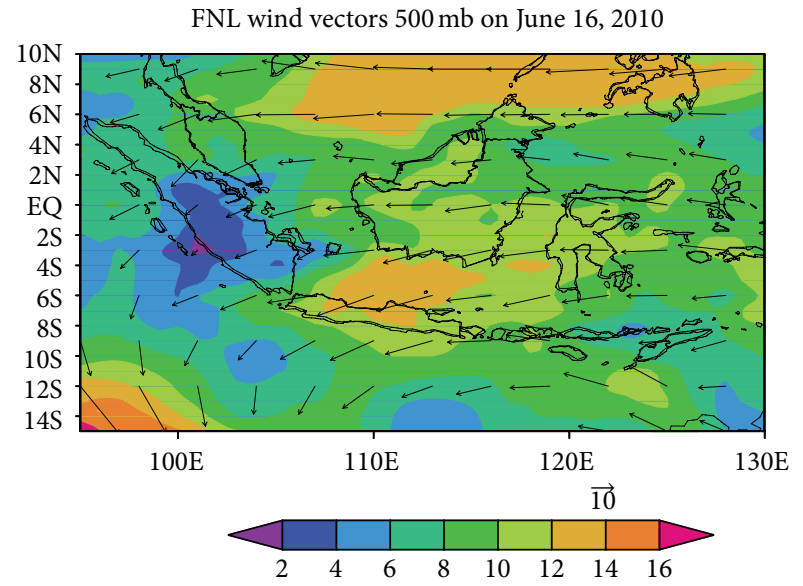

(b)

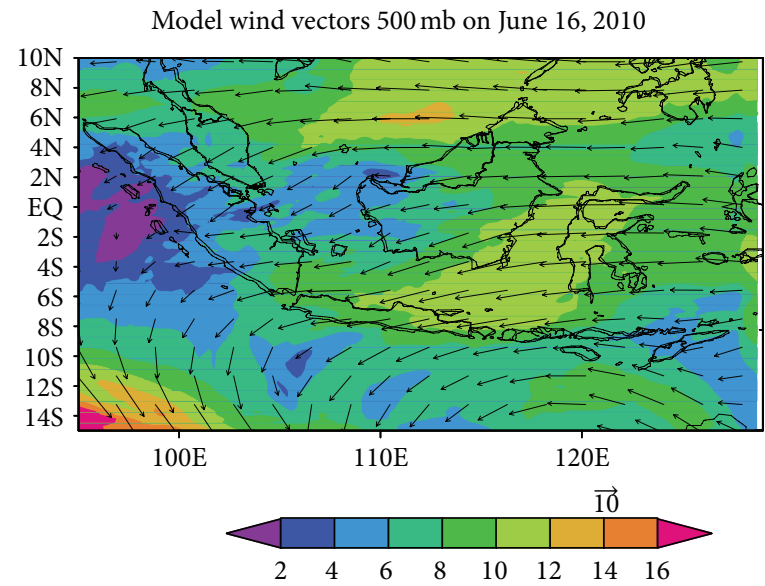

(c)

FIGURE 6: Wind magnitude (shaded) and wind vector (arrow) at $500 \mathrm{mb}$ level on 16th June 2010 (a) GFS, (b) FNL, and (c) model.

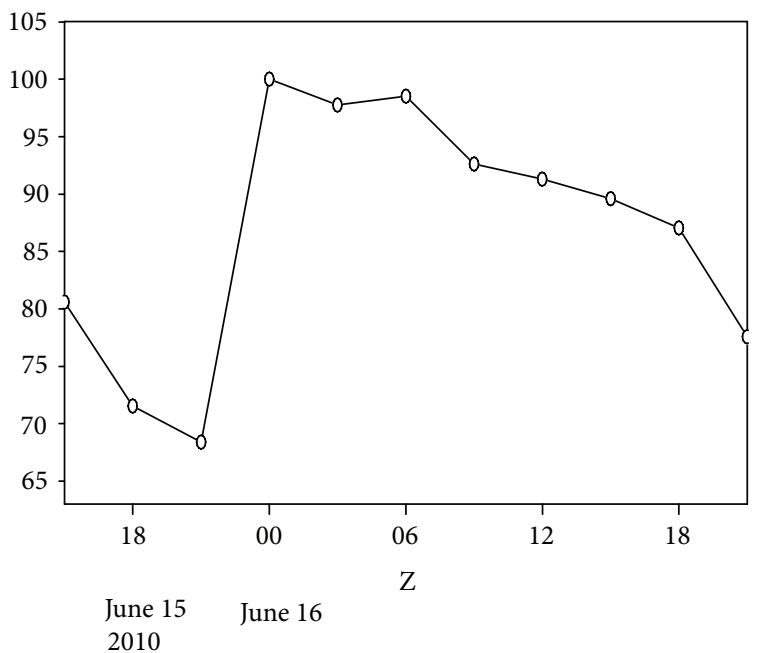

(a)

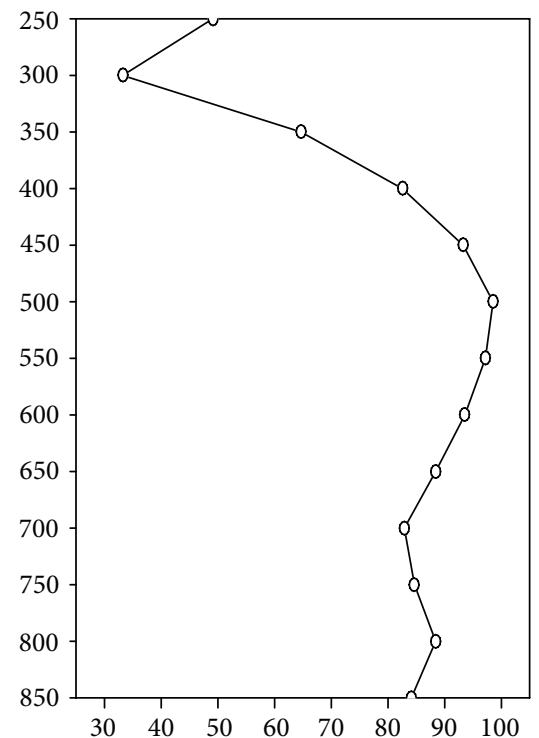

(b)

Figure 7: Model derived relative humidity (RH) at $500 \mathrm{mb}$ level over Singapore (a) and on 00UTC of 16th June 2010 over Singapore with respect to vertical level (b). 


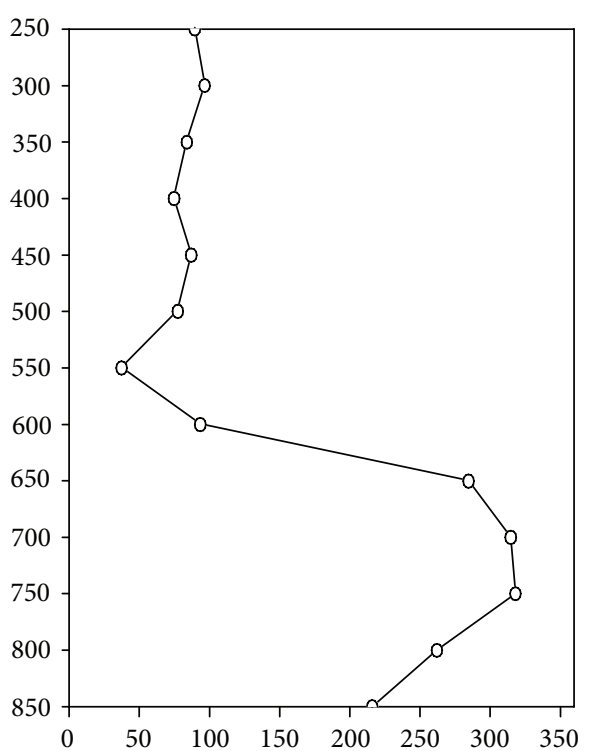

Figure 8: Wind direction (WD) in degrees with respect to vertical levels at Singapore on 00UTC of 16 June of 2010.

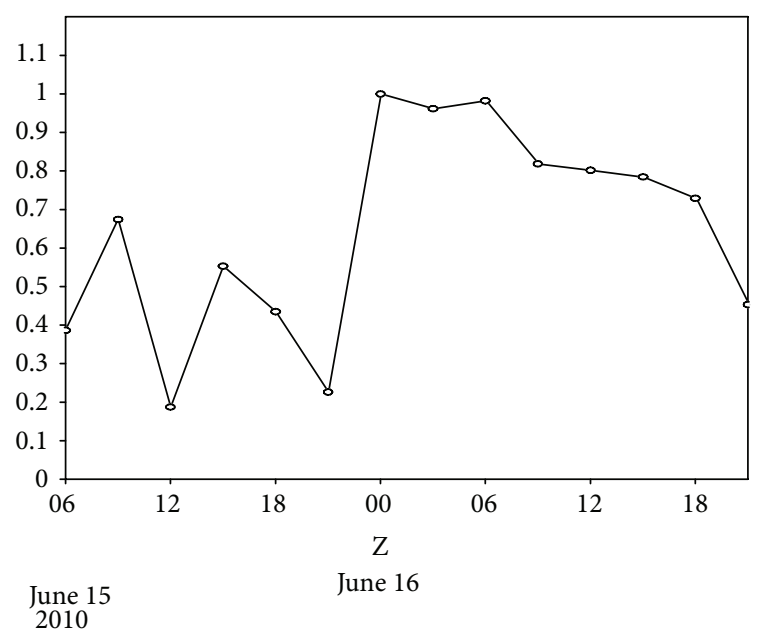

FIGURE 9: Z-component of wind at $250 \mathrm{mb}$ minus Z-component of wind at $850 \mathrm{mb}$ at Singapore.

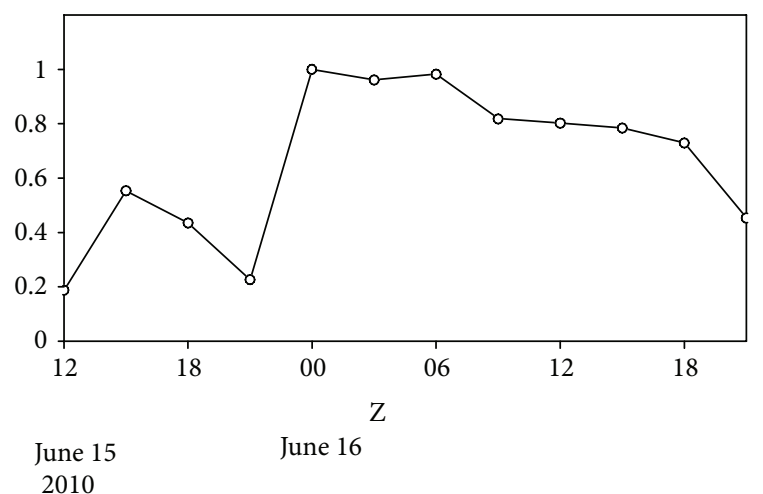

FIGURE 10: Model derived high cloud fraction in percentage over Singapore.

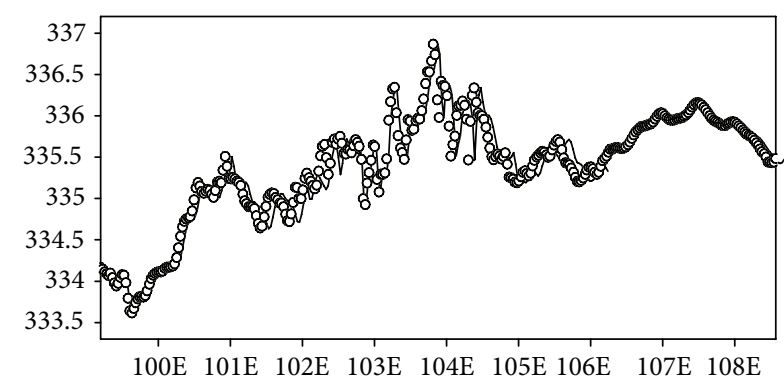

(a)

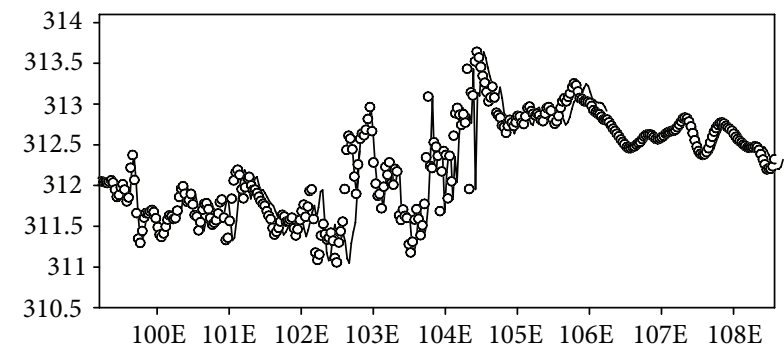

(b)

Figure 11: Potential temperature (in degrees) over Singapore on 00UTC of 16 June 2010 at $400 \mathrm{mb}$ (a) and at $700 \mathrm{mb}$ (b).

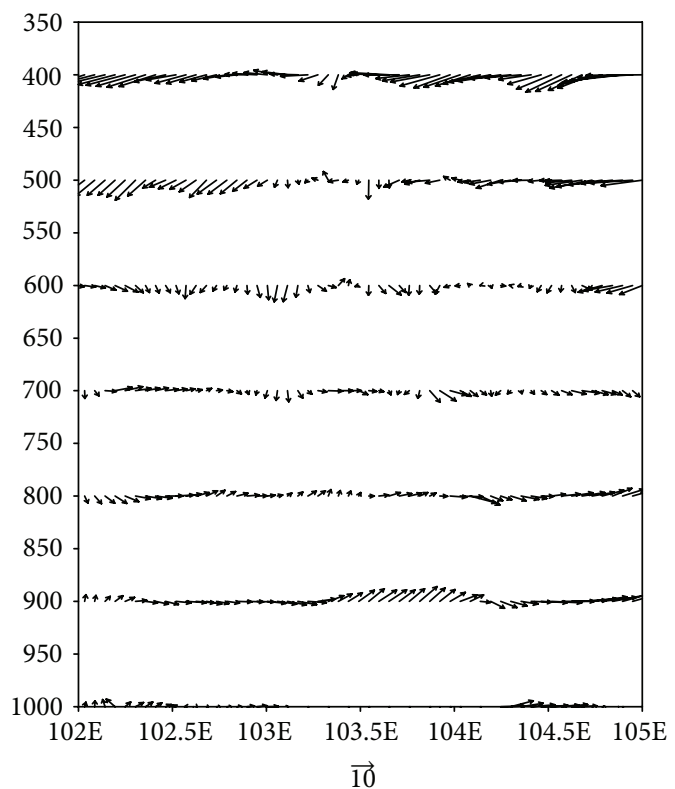

FIGURE 12: Wind vector on 00UTC of the 16th of June, 2010 with respect to vertical levels. $x$-axis represents longitudes.

the prestorm environment that forecasters can readily apply when attempting to assess storm potential on any given day. To the degree that the prestorm environment is known and that convection is going to occur, a forecaster can simply look at the hodograph and determine to a good approximation whether there is sufficient shear over a sufficient depth to 
promote supercell development (e.g., $20 \mathrm{~ms}^{-1}$ of wind variation over the lowest $4-6 \mathrm{~km}$ above ground level). Significant vertical shear presented during the time, and it is speculated that the strong vertical $\mathrm{Z}$ component of wind causes the cloud burst during the event which contributed to heavy rainfall. It is to be noted that model simulations are always sensitive to the initial conditions, domain size and location, model dynamics, and physics, and hence research is still continuing to improve the prediction. From model derived results, we can conclude that the highly localized, heavy rain was the result of an interaction of synoptic-scale weather systems with the mesoscale features.

\section{Acknowledgments}

Dr. B. H. Vaid would like to express his gratitude to the WRF group, GrADs, and Ferret for online support and help. Dr. S. Y. Liong is acknowledged for the kind help and support. The author very much thankful to the reviewers and editor for valuable suggestions and comments, which really helped the author to improve the paper in the present stage.

\section{References}

[1] D. K. Lee, H. R. Kim, and S. Y. Hong, "Heavy rainfall over Korea during 1980-1990," Korean Journal of the Atmospheric Sciences, vol. 1, pp. 32-50, 1998.

[2] A. Routray, U. C. Mohanty, A.K. Das, and N. V. Sam, "Study of HPE over west coast of India using analysis nudging inMM5 during ARMEX-I," Mausam, vol. 56, pp. 107-120, 2005.

[3] H. R. Hatwar, Y. V. Rama Rao, S. K. Roy Bhowmik, and D. Joardar, "An impact of ARMEX data on limited area model analysis and forecast system of India Meteorological Department-a preliminary study," Mausam, vol. 56, pp. 131-138, 2005.

[4] A. K. Bohra, S. Basu, E. N. Rajagopal et al., "Heavy rainfall episode over Mumbai on 26 July 2005: assessment of NWP guidance," Current Science, vol. 90, no. 9, pp. 1188-1194, 2006.

[5] D. R. Sikka and P. Sanjeeva Rao, "The use and performance of mesoscale models over the Indian region for two high-impact events," Natural Hazards, vol. 44, no. 3, pp. 353-372, 2008.

[6] A. Kumar, J. Dudhia, R. Rotunno, D. Niyogi, and U. C. Mohanty, "Analysis of the 26 July 2005 heavy rain event over Mumbai, India using the Weather Research and Forecasting (WRF) model," Quarterly Journal of the Royal Meteorological Society, vol. 134, no. 636, pp. 1897-1910, 2008.

[7] A. Staniforth, "Regional modeling: a theoretical discussion," Meteorology and Atmospheric Physics, vol. 63, no. 1-2, pp. 15-29, 1997.

[8] D. B. V. Rao and D. H. Prasad, "Impact of special observations on the numerical simulations of a HPE during ARMEX-Phase I," Mausam, vol. 56, pp. 121-130, 2005.

[9] Z. I. Janjic, "A nonhydrostatic model based on a new approach," Meteorology and Atmospheric Physics, vol. 82, pp. 271-285, 2003.

[10] A. J. Litta, S. M Ididcula, U. C. Mohanty, and S. K. Prasad, "Comparison of thunderstorm simulations from WRF-NMM and WRF-ARW models over East Indian region," The Scientific World Journal, vol. 2012, Article ID 951870, 20 pages, 2012. 

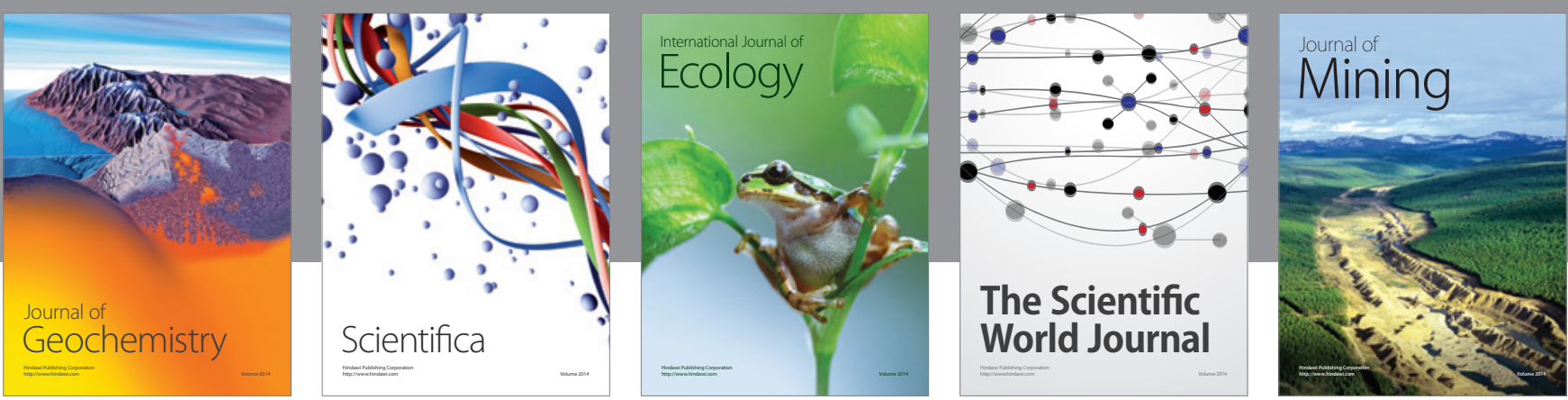

The Scientific World Journal
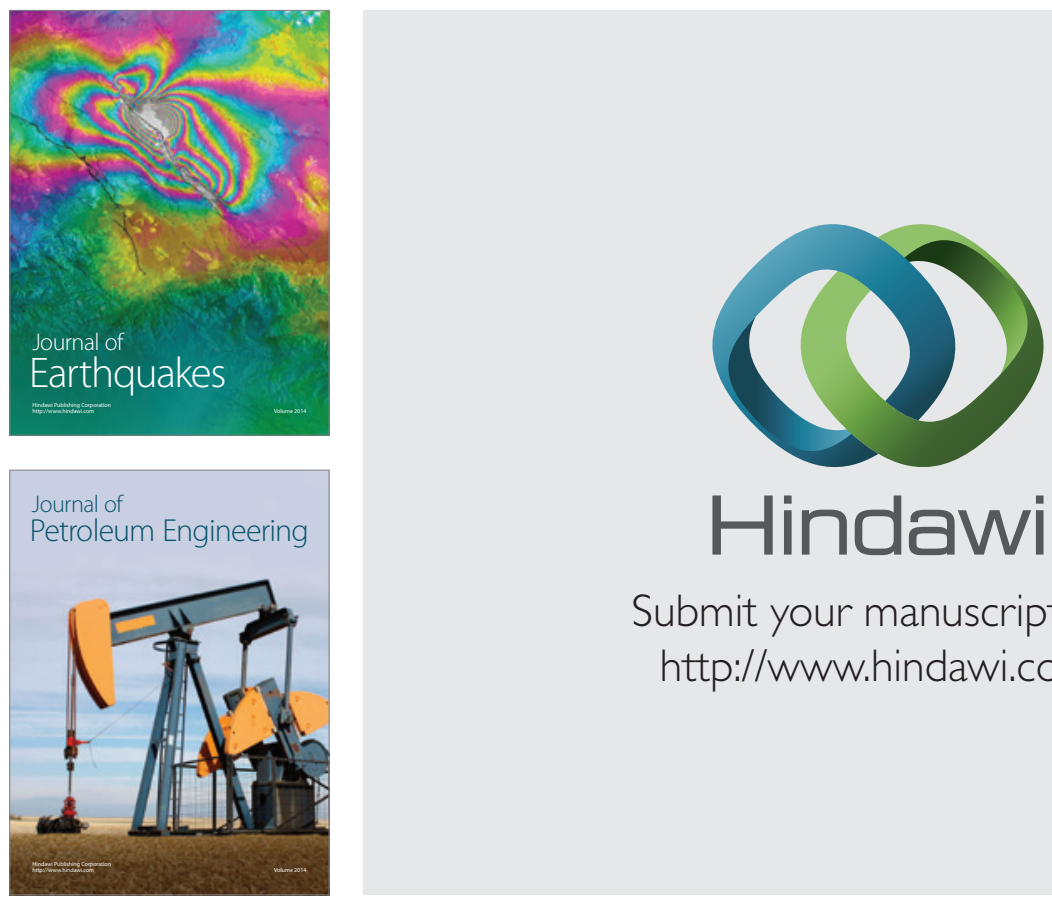

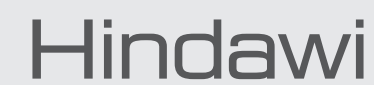

Submit your manuscripts at

http://www.hindawi.com
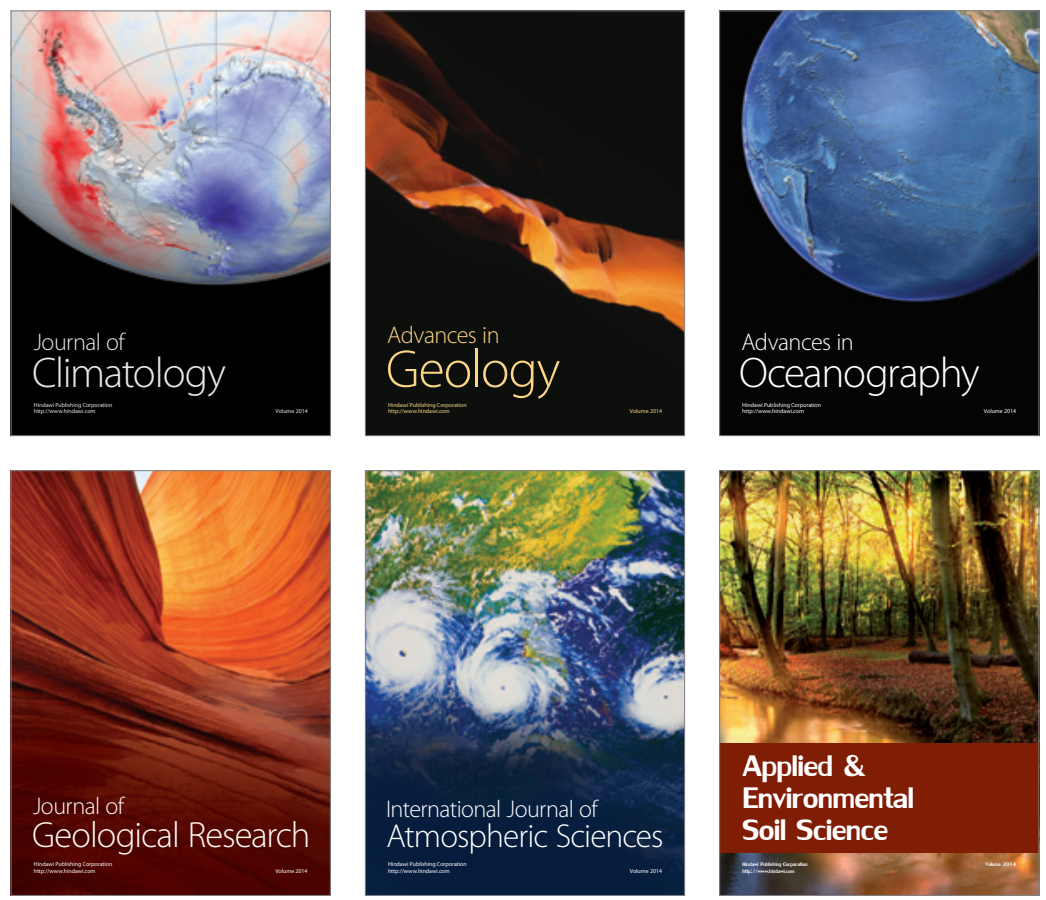
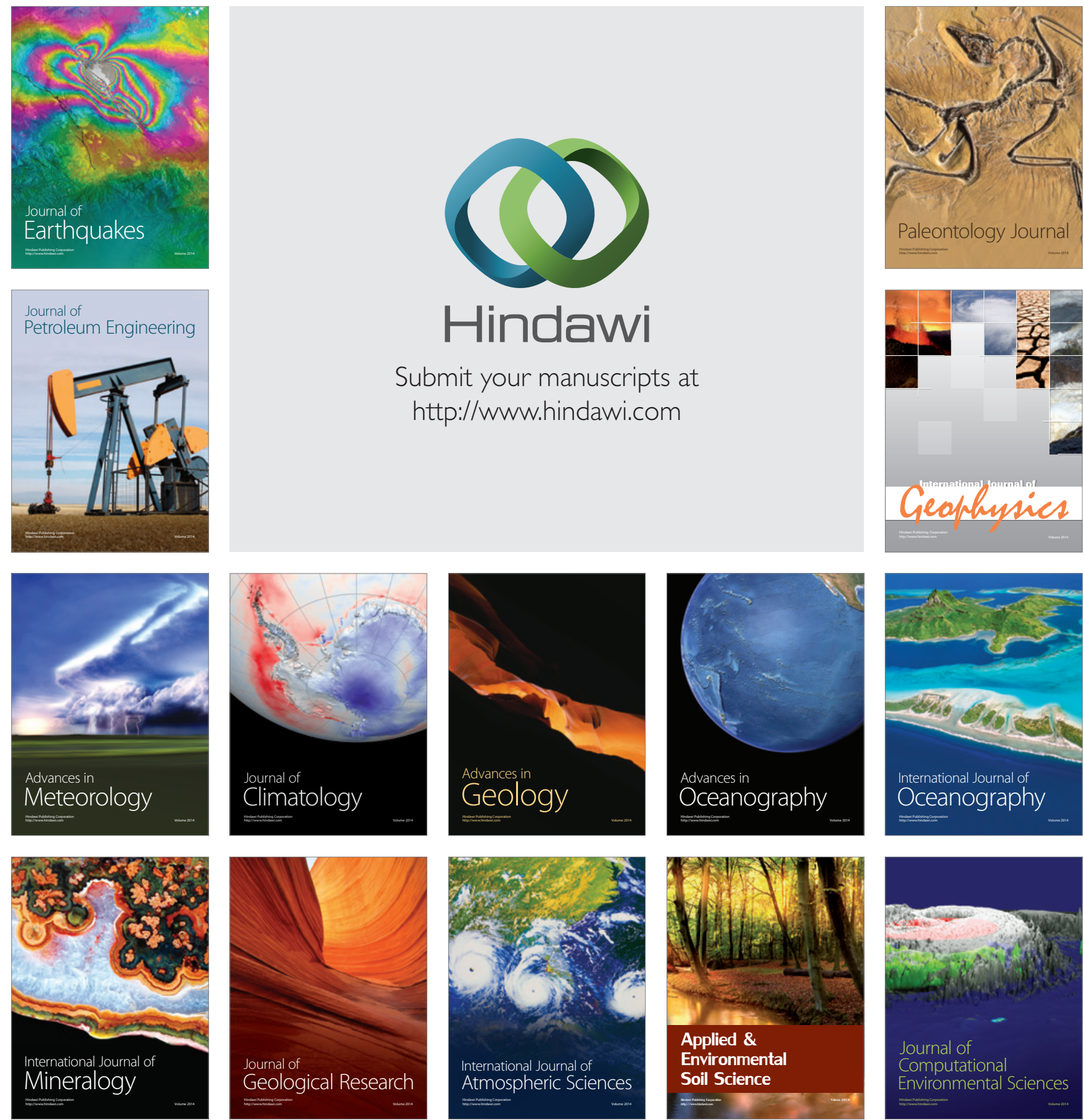